\title{
Удастся ли США изменить систему международной безопасности?
}

\section{Хлестов O.H.*}

Война в Ираке ушла в прошлое. Обострения между США и рядом стран - Францией, Германией, Россией - сглаживаются, чему способствовал ряд встреч глав государств и правительств в Санкт-Петербурге, Эвиане (Франция) и других местах. Сейчас продолжается дискуссия о том, как будут развиваться отношения между Россией и США: высказываются самые различные оценки и предположения. Поскольку обострение произошло из-за войны США против Ирака, необходимо разобраться, из-за чего же «обиделось» руководство США на страны, выступившие против этой войны.

Естественно, руководство США утверждает, что оно поступило правильно. Оценки других стран, их общественности различные. Одни поддерживают США, а другие считают, что они поступили неоправданно, незаконно. Однако для того, чтобы оценить события, происходящие на международной арене, тем более такое серьезное, как вооруженный конфликт, необходимо руководствоваться не эмоциями и не симпатиями к той или иной стране и ее лидерам, а опираться на международное право, устанавливающее правила поведения государств. Только так можно объективно оценить, какие действия государств правомерны, законны, а какие нет.

Современное международное право, созданная на его основе система международной безопасности сложились во второй половине $\mathrm{XX}$ века и коренным образом отличаются от того, что было ранее. Международное право имеет ряд отраслей, начиная от морского и кончая космическим правом. Его наиболее важная часть - принципы и нормы, определяющие, в каких случаях допустимо, правомерно применение вооруженной силы.

На протяжении всей истории человечества война была законным средством осушествления внешней политики и разрешения междуна-

\footnotetext{
* Хлестов Олег Николаевич - Чрезвычайный и Полномочный Посол, Вице-президент Российской Ассоциации международного права.
} 
родных споров. Она использовалась для раздела и передела мира, упрочения позиций мощных держав в различных районах нашей планеты. Лишь в начале XX века появились первые ограничения права прибегать к войне: Устав Лиги наций 1918 года, Парижский договор 1928 года, известный как Пакт Бриана-Келлога.

После разгрома гитлеровской Германии и милитаристской Японии, союзники создали новую систему международной безопасности, воплощенную в Уставе ООН, принятом в 1945 году. Основные ее элементы:

- война как средство осуществления внешней политики и разрешения международных споров запрешена. Государство имеет право применять вооруженную силу лишь в двух случаях: первый - по решению Совета Безопасности ООН и второй - в случае вооруженного нападения на нег. После террористического нападения на США 11 сентября 2001 г. статья 51 Устава ООН была интерпретирована Советом Безопасности ООН и всеми ее членами как признающая право государства на самооборону и в случае террористического нападения на него; сейчас необходимо разработать критерии, какое террористическое нападение дает право на самооборону и как его реализовывать;

- предоставление Совету Безопасности ООН от имени членов этой организации широчайших полномочий для обеспечения мира и безопасности государств, вплоть до применения вооруженной силы-меры принуждения.

Наряду с ними Совет проводит миротворческие операции с использованием вооруженных сил, отличаюшиеся от принудительных мер главным образом тем, что они проводятся с согласия противоборствующих, воюющих сторон. Державы, внесшие основной вклад в разгром фашизма и милитаризма, - СССР, США, Великобритания, Франция и Китай, - являясь постоянными членами Совета Безопасности и обладая правом вето, играют решающую роль в Совете. Кстати, право вето было введено в ООН по инициативе США и неоднократно - примерно 70 раз - применялось ими, что составляет 1/4 всех случаев использования права вето в Совете.

Региональные организации - ОБСЕ, СНГ, ЛАГ и другие - могут проводить миротворческие операции в свонх регионах без санкции со стороны Совета Безопасности, а принудительные меры - только с его согласия (глава VIII Устава ОOH). Любое другое применение вооруженной силы неправомерно (это не затрагивает так называемую законную интервенцию, когда иностранные войска вводятся в пределы 
другого государства с его согласия). Таким образом, международное право, система международной безопасности предоставляют постоянным членам Совета Безопасности ООН широкие права, но в то же время возлагают на них особую ответственность за поддержание мира, требуя координации их действий, поиска компромисса при принятии решений. Все члены ООН, в том числе США и Великобритания, неоднократно подчеркивали свою приверженность существуюшей системе безопасности, международному праву и обязательство его соблюдать: Парижская хартия для новой Европы 1990 года, в которой сказано, что ее участники будут укреплять мир на основе примата международного права; Декларация тысячелетия 8 сентября 2000 г., в которой главы государств и правительств всех членов ООН заявили, что они будут уважать верховенство права и соблюдать его в международных делах.

Иногда роль международного права недооценивается. В представлении недостаточно сведущих людей это какие-то абстрактные, далекие от жизни формулы. Однако это не так. Функционирование этой системы обеспечивает безопасность государств, создает благоприятные условия для их развития, сокрашения военных расходов, повышения благосостояния населения. Международное право, ограничивая произвол мощных держав, служит интересам всех государств, особенно тех, которые не обладают значительным военным потенциалом.

\section{Оценка войны в Ираке}

Их (оценок) было множество, но главным образом с политических, военных и экономических позиций. Оценим ее с точки зрения международного права.

США и Великобритания начали войну против Ирака без разрешения Совета Безопасности ООН. Их попытки добиться такого разрешения были отвергнуты. Совет обеспечивал выполнение Ираком резолюций о разоружении политическими и дипломатическими средствами, включая международную инспекцию, что является наиболее эффективным способом проверки фактов, за что, кстати, обычно выступали и сами США. И это давало положительные результаты. Поэтому начинать военные действия для разоружения Ирака не было никакой необходимости. Тем более что сейчас появляется все больше информации о том, что руководители США и Великобритании преувеличивали угрозу создания и использования Ираком оружия массового уничтожения. Несостоятельными являлись и доводы США и 
Великобритании о том, что они защищали права человека, освобождая население Ирака от диктатора: международное право не предоставляет государствам право применять вооруженную силу для защиты прав человека в другой стране или смены там существуюшего правительства. Лишь Совет Безопасности ООН может применять любые санкции, в том числе и военные, против члена ОOН, если Совет сочтет это необходимым, в том числе и в случае серьезных, массовых нарушений прав человека.

Неоправданными являются и раздающиеся голоса, что США осуществляли право на самооборону: их военные действия далеко выходили даже за рамки интерпретации самообороны, изложенной в Национальной стратегии безопасности США (утверждена в сентябре 2002 г.); она допускает осуществление «опережаюших действий» (preemptive) при возникновении «непосредственной угрозы» (imminent threat). Ирак не мог создавать США непосредственную угрозу - его войска были разгромлены за один месяц и американцы не могли не знать в каком состоянии они находятся, а военные действия США, начавшиеся против Ирака за тысячи километров от них никак не походили на опережающие.

Таким образом, США и Великобритания, начав военные действия против Ирака, совершили тягчайшее нарушение Устава ООН, своих международных обязательств. Как же реагировало на это международное сообщество?

Для сравнения уместно напомнить, что подобные действия США, совершенные ранее, решительно осуждались мировым сообшеством. Так, военное нападение США на Ливию в 1986 году было расценено как «нарушение Устава ООН и норм международного права) (резолюция ГА ООН 41/38 от 20 ноября 1986 г.). Еще более резко была осуждена военная интервенция США в Панаму в 1989 году: Генассамблея ООН назвала ее «...вопиющим нарушением международного права, независимости, суверенитета и территориальной неприкосновенности...» Панамы, подчеркнув право этого государства «...свободно определять свою социальную, экономическую и политическую систему...» (резолюция 44/240 от 29 декабря 1989 г.). Сейчас обстановка в мире иная - $\mathrm{OOH}$, другие международные организации не сумели выступить против США и Великобритании, и даже правительства мусульманских стран, чье население активно протестовало в связи с нападением на Ирак, занимали уклончивую позицию. В этих условиях 
позиция Франции, России, Китая, Германии, выступивших против войны, заслуживает самой высокой оценки; они руководствовались не эгоистическими интересами - получение долгов от Ирака (что вообще эфемерно в ближайшее время), стремление сохранить контракты на разработку нефти в Ираке (кстати, никто не доказал, что это выгодно для бюджета России). Эти страны выступили, причем очень взвешенно, за соблюдение Устава ООН, международного права, и позиция США выглядит странно - нарушители права, начавшие войну, «обиделись» на тех, кто защищал права, хотя США и Великобритания активно выступают за демократию, а ее основа - соблюдение законности, права.

\section{Сумеют ли США изменить систему международной безопасности?}

Возникает вопрос: что будет дальше? Ограничатся ли США «спасением» мирового сообщества только от Ирака или пойдут дальше по такому же пути? В последнее время не раз раздавались угрозы со стороны США в адрес Ирана, Сирии. Будут ли они реализованы - вопрос спорный; имеются разные точки зрения. Но что ясно проглядывает, так это стремление руководства США применять вооруженную силу в обход Совета Безопасности ООН и закрепить за США право применять ее там и тогда, когда они сочтут это необходимым. Причем это происходит на фоне оживления в США концепции бремени белого человека, которая использовалась для оправдания колониализма, а также рассуждений об ответственности США за поддержание международной стабильности и демократии, поскольку ООН якобы не в состоянии это делать.

Возникает вопрос: удастся ли руководству США добиться своих целей? Сейчас они являются самой мощной державой. На долю США приходится 1/3 мирового ВВП. Их военный бюджет - 300 млрд. долларов - в два раза больше военного бюджета всех стран Евросоюза, вместе взятых.

США заслуживают уважения, когда направляют свою мощь на благо человечества, на решение таких задач, как борьба с международным терроризмом, защита окружаюшей среды, ликвидация болезней, борьба с нищетой и голодом. Но сейчас положение иное: линия США создает угрозу мировому сообществу, всем странам и народам, и пора ударить в набат. 
Оценивая развитие событий, можно сделать вывод, что США все же не удастся изменить существуюшую систему международной безопасности, международное право в силу объективных факторов. Остановимся на некоторых из них.

1. Роль международного права в XXI веке будет возрастать под влиянием НТР, глобализации, причем усиливается тенденция к созданию международных организаций и учреждений, в том числе судебных, в целях повышения эффективности международно-правовых норм: создание Международного трибунала ООН по морскому праву, Международного уголовного суда (Римский статут ратифицировало уже более 100 государств), международных трибуналов по Югославии, Руанде и Сьерра-Леоне, европейских судов. Различные международные органы, например, Комиссия ООН по правам человека, все более наделяются правом контроля за выполнением государствами международных обязательств. Попытки возродить правомерность использования войны для разрешения споров - это стремление повернуть развитие человечества вспять. Но остановить прогресс невозможно.

2. Осуществление линии США, подрывающей систему международной безопасности, создало бы угрозу малым странам, так как вслед за США и другие крупные державы стали бы вновь прибегать к войне. Использование США вооруженной силы в нарушение права подталкивает к аналогичным действиям и другие державы. Вот и руководство КНДР прибегло к атомной дипломатии, угрожая созданием и применением ядерного оружия. Что касается постоянных членов Совета Безопасности ООН - России, Франции и Китая, то их позиции в вопросах применения санкций были бы существенно подорваны, а влияние на международные дела ослаблено. Поэтому эти страны будут неизбежно выступать против девальвации роли Совета. Как показывает опыт, такую же позицию будут занимать и многие другие, как крупные (Германия, Индия), так и небольшие государства (Бельгия, Нидерланды - родина Гуго Гроция, внесшего огромный вклад в развитие международного права).

3. США не могут изменить Устав $\mathrm{OOH}$ без согласия других постоянных членов Совета Безопасности: поправки к Уставу должны быть поддержаны ими в Совете и затем ратифицированы. Наивно ожидать, что Россия, Франция и Китай пойдут на это. Следовательно, использование США вооруженной силы вопреки положениям Устава ООН явится нарушением международного права, а нарушение права не создает право. 
4. Военные действия против Ирака привели к усилению антиамериканизма не только в мусульманских, но и в других, в том числе европейских, странах. Свергнув правительство С. Хусейна и став оккупирующей державой, США при управлении Ираком сталкиваются с серьезными трудностями, поскольку в стране существует масса сложных политических, экономических, социальных, религиозных и национальных проблем. США не обеспечивают нормальное положение, нормальную жизнь в Ираке, что должна делать оккупирующая держава согласно международному праву. В случае проведения неправомерных военных действий против других стран эти трудности, как и в Афганистане, будут возрастать и ложиться тяжелым бременем на плечи американцев. Это также усилит антиамериканские настроения, что может негативно сказаться на сотрудничестве США с другими странами в сферах, представляющих для них интерес, например борьба с международным терроризмом. Последние события показывают, что в США начинают понимать, что участие $\mathrm{OOH}$ в урегулировании положения в Ираке отвечает и интересам США, в связи с чем они все больше выступают за активизацию ООН в этом процессе. И хотя не исключено, что американцы стремятся лишь использовать ООН в виде ширмы, сохраняя за собой решающую роль, участие ООН голезно; но, естественно, при максимальном влиянии на развитие событий в Ираке.

\section{Борьба за сохранение международного права}

Поскольку линия США направлена на разрушение сердцевины международного права - системы международной безопасности, задача мирового сообщества - организовать защиту этого права. И это долг всех стран. Крупные державы - Россия, Франция, Китай, Германия, Индия, Мексика - могли бы быть лидерами в этой борьбе.

Порой раздаются голоса, что критика США, противодействие их линии на подрыв системы международной безопасности недопустимы, так как это может привести к ухудшению отношений с ними, в том числе и России. Но на международной арене происходит не только сотрудничество, но и борьба, поскольку интересы государств порой не совпадают. Международное право содержит целую систему способов и средств для мирного разрешения международных противоречий и споров: переговоры, добрые услуги, посредничество, следственные и согласительные комиссии, арбитраж, судебные процедуры, международные организации, в особенности СБ ООН. Задача - более эффек- 
тивно использовать эти средства. Россия, как и другие державы, особенно постоянные члены Совета Безопасности, не может не защищать свои позиции на международной арене, в ООН, и это должны понять американцы, тем более что Россия обычно поддерживает правомерные действия США. Примеры - события в Афганистане. США расценили террористическое нападение 11 сентября как вооруженное нападение, в связи с чем возникает право на самооборону по ст. 51 Устава ООН. Россия активно поддержала этот подход, в том числе и в Совете Безопасности ООН, который подтвердил позицию США. Наша страна рассматривала военные действия американцев против талибов в Афганистане как правомерные, содействуя их осуществлению, что было полезно для США'

То же самое в борьбе с международным терроризмом. Россия действует совместно с США, в том числе в Совете Безопасности ООН и его Антитеррористическом комитете. Есть масса других сфер, где Россия, как и иные державы, могла бы плодотворно сотрудничать с США: освоение космоса, исследования нашей планеты, различные социальные проблемы и т.п.

-Таким образом, возможная негативная реакция руководителей США на защиту Россией ее законных прав и интересов, международного права, системы международной безопасности не должна выходить за рамки обычных отношений между государствами, как это было у США с Евросоюзом, Японией, Китаем, Индией, несмотря на возникавшие порой обострения. И преувеличивать значение обострения отношений между Россией и США, если Россия будет выступать в защиту международного права, не следует. $\mathrm{K}$ тому же США и сами порой создают проблемы для России, как, например, полеты их разведывательных самолетов вдоль границ Российской Федерации с Грузией, на что Россия, естественно, не может не реагировать.

Защищая существующую систему международной безопасности, необходимо принять меры для ее совершенствования, учета интересов и тех, кто не полностью удовлетворен этой системой. План мероприятий в этой области, который следовало бы разработать, в частности, и в России, мог бы включать следующие элементы:

1. Повышение эффективности международных органов с целью обес-

1 Подробнее об этом см. статью «Вооруженная борьба против международного терроризма (политико-правовые аспекты)», опубликованную в «Московском журнале международного права». 2003. №4. 
печения выполнения международно-правовых норм, международных обязательств государств, и в первую очередь Совета Безопасности ООН. В Комитете по пересмотру Устава ООН имеется немало предложений о повышении роли ООН и ее Совета Безопасности, которые могут быть использованы. Один из вопросов - расширение числа постоянных членов Совета, с тем чтобы он пользовался большей поддержкой. Можно было бы ввести в Совет полупостоянных членов от различных регионов, например Германию и Японию от западных стран, Бразилию и Аргентину или Мексику от латиноамериканских государств, Индию и Пакистан или Индонезию от Азии, Нигерию и Египет от Африки. Эти страны входили бы в Совет как постоянные члены поочередно, на orраниченный срок, например на два года, и избирались бы странами своего региона. Можно было бы также подумать о том, чтобы они пользовались правом вето в отношении дел, касающихся их региона.

Что касается полномочий Совета Безопасности, то он должен больше уделять внимания вопросам, которые в современных условиях вызывают особый интерес у мирового сообщества, таким как борьба с международным терроризмом, чем уже занимается Совет, предотвращение распространения оружия массового уничтожения, защита прав человека. Поскольку правам человека сейчас придается особое внимание, Совет Безопасности мог бы специально рассматривать эту проблему. Учитывая критику в адрес Совета в связи с тем, что он не предотвратил геноцид в Камбодже, Совет мог бы создать специальный комитет для борьбы с международным терроризмом и разработать критерии, которыми Совет будет руководствоваться в случае грубых, массовых нарушений прав человека в той или иной стране, включая применение санкций, в том числе и военных. При этом во всех случаях, когда может возникать необходимость использования вооруженной силы для урегулирования проблем, возникающих в этих сферах отношений между государствами, вопрос об использовании таких сил может решаться только Советом Безопасности ООН.

В современных условиях военные расходы, особенно в связи с возрастанием стоимости военной техники, поглощают значи гельную часть бюджета многих стран. Было бы полезно наращивать в ООН усилия для сокращения военных расходов и использования высвобождающихся средств для повышения благосостояния народов всех стран.

2. В ООН уже принимались решения о повышении роли региональных организаций, о которых речь идет в главе VIII Устава ОOH, в под- 
держании мира: например, Декларация ООН 1994 года (резолюция 49/ 57 от 9 декабря 1994 г.). И эта линия оправданна, так как страны региона могут со знанием дела решать возникаюшие там вопросы. Известно, что государства Африканского континента разработали договор о применении принудительных мер по их инициативе, не учитывая ст. 53 Устава ООН. В этих условиях Совет мог бы, исходя из этой статьи, уполномочить региональные механизмы на проведение принудительных мер, если страны региона разработали и приняли соответствующую международно-правовую норму. Это отвечало бы интересам стран региона и вело бы к более широкой поддержке ими ООН.

3. В настоящее время миротворческие операции ООН с участием вооруженных сил проводятся по решению Совета Безопасности, хотя первая операция в 1956 году была осуществлена по решению Генеральной Ассамблеи ООН. Поскольку миротворческие операции проводятся с согласия противоборствующих, воюющих сторон и имеют иные задачи, чем принудительные меры, эти операции можно было бы проводить и по решению Генеральной Ассамблеи, что повышало бы роль всех членов ООН в рассмотрении вопросов поддержания мира.

4. Сейчас в США, а порой и в других странах, в том числе и в нашей, раздаются голоса, что ООН бесполезная организация, не сумела предотвратить многие вооруженные конфликты, изжила себя и на ее смену необходимо создать новую организацию. Подобные утверждения неоправданны и выдвигаются иногда, скорее для того, чтобы дискредитировать ООН. Однако эта организация и связанные с ней международные организации (специализированные учреждения ООН и МАГАТЭ - их около 20), именуемые «семья ООН» сыграли и продолжают играть огромную роль в развитии человечества. Сферы, в которых успешно осуществляется международное сотрудничество в рамках этих организаций, трудно перечислить. Это промышленность, и в первую очередь атомная, сельское хозяйство, мореплавание, охрана окружающей среды, здравоохранение, метеорология, авиация, освоение космоса и т.д. Особую роль ООН сыграла в развитии международного права: во второй половине XX века в этой области было сделано больше, чем за два предыдущих столетия. Например, права человека. После принятия Устава ООН, Всеобщей Декларации прав человека и разработки в рамках ООН ряда международных договоров права человека стали не внутренним делом государства, как это было ранее, а международной проблемой. Ныне политическая, дипломатическая за- 
щита прав человека в другой стране не является вмешательством во внутренние дела государства, и это имеет огромное значение для защиты прав граждан во всех странах.

ООН не сумела предотвратить некоторые вооруженные конфликты, возникавшие после второй мировой войны, но Это было связано с существовавшей в мире сложной геополитической обстановкой, холодной войной, другими факторами. Но даже в этой сфере ООН сумела достичь определенных положительных результатов. В последние десятилетия ООН провела свыше 50 миротворческих операций более чем в 30 районах мира, причем 80\% из них - внутренние вооруженные конфликты. В операциях участвовало свыше 700 тысяч военнослужащих и других лиц из 80 стран. В результате миротворческих операций ООН была сохранена или восстановлена государственность таких стран, как Камбоджа, Восточный Тимор, прекращены вооруженные конфликты, например между Эритреей и Эфиопией, сохранены миллионы жизней. Сейчас ООН в связи с прекращением холодной войны и изменением мировой обстановки наращивает свою миротворческую деятельность ${ }^{2}$. В современных условиях успешное развитие науки, техники, медицины и всех других направлений деятельности человека возможно лишь в результате совместных усилий государств, что сказывается, в частности, на создании множества международных, межгосударственных организаций. Если после второй мировой войны их было 2-3 десятка, то сейчас - свыше 270. Главенствующую роль среди них играет ООН. А создать вместо нее другую организацию нереально. Поэтому разговоры о бесполезности ООН, ее ликвидации похожи на стремление лить воду на американскую мельницу. В этих условиях объективное освещение роли и значения ООН - долг и задача всех членов мирового сообщества, неправительственных организаций, средств массовой информации.

Нередко выступления в защиту ООН, и особенно международного права, воспринимаются политиками, государственными деятелями как наивность. Главное, по их мнению, - это политика, а международное право, международные инструменты, созданные на его основе, в том числе ООН, это что-то второстепенное. Это глубокое и очень опасное заблуждение, которое, к сожалению, довольно распространено. Политика должна осуществляться в рамках норм международного права при

${ }^{2}$ Подробней об этом см. доклады Генерального Секретаря ООН Кофи А. Аннана, представленные Генеральной Ассамблее ООН в 2000, 2001 и 2002 гт. 
соблюдении государствами их международных обязательств. Человечество достигло высочайших успехов в технике, медицине: стоит на пороге клонирования человека, освоения других планет. Однако оно до сих пор не научилось разумно, мирными средствами разрешать возникающие разногласия и противоречия на своей собственной планете. Путь развития международного сообщества - это упрочение международного права, его неуклонное соблюдение, повышение роли $\mathrm{OOH}$. И чем скорее поймут это политики, государственные деятели, тем быстрее будут исчезать вооруженные конфликты, которые в свете развития военной техники становятся все более кровавыми и разрушительными.

5. Евросоюз превратился в мошное объединение государств. Численность его населения превышает численность населения США, а доля в мировом ВВП составляет $1 / 3$. Европейские государства, их парламенты, общественность относятся к международному праву с большим уважением, чем США. И хотя во время войны в Ираке мнения ряда европейских стран разошлись, Евросоюз стремится консолидировать позицию входящих в него стран по международным вопросам. Есть основание полагать, что Евросоюз, где большое значение придают роли права, будет поддерживать и существующее международное право, систему международной безопасности. Сейчас Евросоюз создает свои вооруженные силы численностью до 60 тыс. человек. В их задачи будет входить проведение миротворческих операций как в Евpone, так и за ее пределами. России было бы полезно активнее сотрудничать с Евросоюзом по вопросам международного права и создания вооруженных сил этого союза как с военным формированием регионального характера.

Разумеется, что перечень подобных предложений мог бы быть расширен. 